\title{
A INSTITUCIONALIZAÇÃO DA EDUCAÇÃO AMBIENTAL NO LICENCIAMENTO: UMA POLÍTICA PARA A PARTICIPAÇÃO SOCIAL NA GESTÃO AMBIENTAL PÚBLICA
}

\author{
Noa Magalhães ${ }^{1}$ \\ Carlos Frederico Bernardo Loureiro ${ }^{2}$
}

\begin{abstract}
Resumo:
O presente trabalho faz uma revisão descritiva do desenvolvimento do constitucionalismo e evolução das diretrizes jurídicas da política ambiental brasileira, tratando, especificamente, da educação ambiental no âmbito do licenciamento offshore de petróleo e gás, enquanto medida mitigadora e compensatória dos impactos ambientais da cadeia produtiva do petróleo. Descreve suas diretrizes políticas e jurídicas (como leis, decretos, resoluções, normas técnicas, instruções normativas), entre outros documentos do âmbito da educação ambiental, construídas ao longo de quatro décadas no país. O artigo conclui que a educação ambiental no licenciamento institucionaliza, no âmbito do Estado, a defesa de um processo educativo que estimule iniciativas populares, qualificando e mobilizando os grupos sociais para participarem da gestão de seus territórios, portanto, de uma gestão ambiental pública e democrática.
\end{abstract}

Palavras-chave: Gestão Ambiental. Licenciamento Ambiental e Educação Ambiental.

\section{THE INSTITUTIONALIZATION ENVIRONMENTAL EDUCATION IN LICENSING: A POLICY FOR SOCIAL PARTICIPATION IN ENVIRONMENTAL MANAGEMENT PUBLIC}

\begin{abstract}
:
The present study is a descriptive review of the development of constitutionalism and evolution of the legal guidelines of the Brazilian environmental policy, especially environmental education under the Licensing Offshore oil and gas as a constraint and compensatory mitigation measure and the environmental impacts of production chain oil. Describes the policies and legal guidelines as laws, decrees, resolutions, technical standards, normative statements, among other documents the scope of environmental education, which has been built over four decades in the country. In search of an educational process that stimulates, popular initiatives and qualify social actors to participate in the environmental management of their territories for a democratic and participatory public environmental management.
\end{abstract}

Keywords: Environmental Management. Environmental Permitting and Environmental Education.

\footnotetext{
${ }^{1}$ Doutoranda do Programa de Pós-Graduação em Meio Ambiente da Universidade do Estado do Rio de Janeiro (UERJ).noamaga@gmail.com

${ }^{2}$ Professor dos programas de pós-graduação em Educação e em Psicossociologia de Comunidades e Ecologia Social (UFRJ). Líder do Laboratório de Investigações em Educação, Ambiente e Sociedade (LIEAS/UFRJ). floureiro@openlink.com.br
} 


\section{LA INSTITUCIONALIZACIÓN DE LA EDUCACIÓN AMBIENTAL EN LA CONCESIÓN DE LICENCIAS: UNA POLÍTICA DE PARTICIPACIÓN SOCIAL EN LA GESTIÓN AMBIENTAL PÚBLICA}

\section{Resumen:}

Este trabajo es una revisión descriptiva del desarrollo del constitucionalismo y la evolución de las directrices legales de la política ambiental brasileña, dirigiéndose, específicamente, a la educación ambiental en la concesión de licencias offshore de petróleo y gas, en cuanto sea una medida de mitigación y compensación de los impactos ambientales de la cadena de producción del petróleo. Describe sus orientaciones políticas y legales (tales como leyes, decretos, resoluciones, normas técnicas, instrucciones normativas), y otros documentos del ámbito de la educación ambiental, construidas hace más de cuatro décadas en el país. El artículo concluye que la educación ambiental en la concesión de licencias institucionaliza, bajo la defensa del Estado, un proceso educativo que fomenta las iniciativas de base, la calificación y la movilización de los grupos sociales a participar en la gestión de sus territorios, por lo tanto, una gestión ambiental pública y democrática.

Palabras-clave: Gestión Ambiental. Licencias Ambientales y Educación Ambiental.

\section{Introdução}

A grande maioria dos resgates da história ambientalista mundial, em termos institucionais, traz a I Conferência das Nações Unidas sobre o Meio Ambiente ${ }^{3}$ (CNUMAH) como um marco nas discussões internacionais sobre as alternativas para a preservação ambiental, o uso dos recursos naturais e sobre os limites da ação humana no planeta. A conferência discutiu a gravidade da associação entre os cinco fatores básicos do desenvolvimento (população, produção agrícola, recursos naturais, produção industrial e poluição) e buscou soluções para os problemas ambientais, sob a perspectiva de governabilidade da sociedade moderna capitalista e do desenvolvimento sustentável (LOUREIRO, 2003). Nesta, discutiu-se, também, a necessidade de se vincular a educação à questão ambiental. Nesse escopo, caberia à educação ambiental um papel central não somente no que chamaram de conscientização de indivíduos acerca das questões ambientais, mas, também, na participação e controle social para o uso dos recursos naturais, ainda que sob os marcos de uma democracia liberal (LA PRESTRE, 2000; SOUZA; NOVICKI, 2010).

Outra característica marcante do encontro, com representantes de 113 nações ao redor do mundo, foi a divergência entre as perspectivas ambientais dos países participantes. Países industrializados, com um histórico de exploração dos recursos naturais e que enfrentavam sérios problemas ambientais como a poluição e a escassez de recursos em seus territórios, se mostravam preocupados com os efeitos da devastação do planeta. Tais países estavam propondo complexas medidas de controle e preservação de recursos naturais e genéticos que, em muitos casos, deveriam ser aplicadas em outros países. Em contrapartida, países como o Brasil, que vivia o milagre econômico ${ }^{4}$, e que se encontravam na periferia do desenvolvimento capitalista mundial não pretendiam retardar o aspirado crescimento da economia em detrimento da preservação ambiental (MACHADO, 2006; GUSMÃO; DI

\footnotetext{
3 Também conhecida como Conferência de Estocolmo, realizada em 1972, pela Organização das Nações Unidas - ONU.

4 Período entre os anos de 1969 e 1973 marcado por forte crescimento da economia, alavancado pelo PAEG (Programa de Ação Econômica do Governo) implantado em 1964, durante o governo de Castelo Branco.
} 
MARTINI, 2009), postos como aspectos antagônicos. O Brasil não possuía, à época, uma política ambiental unificada, formulada em Lei.

A partir da década de 1970, nações ao redor do mundo, passaram a buscar medidas para compatibilizar interesses políticos, econômicos, sociais e a preservação dos recursos naturais. As soluções e propostas para a superação da crise ambiental giravam em torno do mercado e da aceleração do crescimento econômico, garantindo (hipoteticamente) por meio da gestão ambiental a compatibilidade entre preservação ambiental e justiça social.

Contudo, no marco de uma sociedade capitalista, estruturalmente evidenciada como excludente e desigual, em que as classes dominantes têm força soberana na configuração do Estado e exercem forte influência na produção das políticas e suas diretrizes, não parece existir elementos de realidade que indiquem a possibilidade de justiça social ou ambiental (ACSELRAD, 1999; HARVEY, 2011). Por outro lado, mesmo cientes das determinações sociais existentes, as contradições da sociedade evidenciam que as lutas sociais abrem possibilidades de conquistas de direitos e avanços em políticas públicas de responsabilidade do Estado. Nesse contexto, entende-se que o licenciamento ambiental é um instrumento estratégico do processo de gestão ambiental pública, merecedor de atenção especial por parte dos que se situam na perspectiva da justiça ambiental.

Hoje, dentre os componentes do licenciamento ambiental, tem-se a educação ambiental como um elemento estruturante de espaços públicos na gestão ambiental e de fomento à organização e mobilização popular. As propostas educativas visam, desse modo, ao fortalecimento de grupos sociais vulneráveis e impactados por empreendimentos, buscando reverter a reprodução das desigualdades ambientais. Para tanto, é fundamental que estes grupos tenham poder de participação nas decisões e na construção de políticas ambientais em seus territórios (IBAMA, 2005; QUINTAS, 2005). Para se atingir tais objetivos, a educação ambiental crítica, implementada como medida mitigadora, é posta como um instrumento para a potencialização da participação e do controle social das políticas públicas e da gestão ambiental pública (IBAMA, 2005).

O presente trabalho faz uma revisão descritiva do desenvolvimento do constitucionalismo e evolução das diretrizes jurídicas da política ambiental brasileira, especialmente da educação ambiental no âmbito do licenciamento offshore de petróleo e gás (as leis, decretos, resoluções, normas técnicas, instruções normativas, entre outras diretrizes e instrumentos jurídicos). Tais diretrizes vêm sendo construídas desde a década de 1990, na busca de um processo educativo que estimule, informe e fortaleça iniciativas populares, qualificando e mobilizando os grupos sociais a participarem da gestão ambiental de seus territórios.

\section{O início da política ambiental brasileira e a educação ambiental}

Desde a década de 1920, havia no Brasil uma crescente formação da classe operária e acontecia o surgimento dos sindicatos e outras organizações do meio operário, estudantil e universitário (MONTAÑO; DURIGUETTO, 2010). Essas organizações, que protagonizavam a luta pela transformação da sociedade, vinham em um movimento de intenso ativismo ${ }^{5} \mathrm{e}$ campanha pela participação popular nas decisões dos problemas nacionais. Esse processo foi interrompido em 1964, e, respaldando-se no binômio ideológico segurança e desenvolvimento

\footnotetext{
5 Podemos citar uma das maiores manifestações grevistas de toda a história do movimento operário brasileiro que ocorreu em São Paulo, no ano de 1963, com a presença de setecentos mil trabalhadores. No ano seguinte, no Rio de Janeiro, duzentos mil trabalhadores fizeram um ato pelas reformas de base. Em 1964, iniciou-se uma longa noite do sindicalismo brasileiro. (MONTAÑO; DURIGUETTO, 2010).
} 
instaurou-se uma política de restrição e opressão aos movimentos sociais e a qualquer manifestação que representasse ameaça à ordem pública (CASTRO; CANHEDO JR. 2005; MIRANDA; CASTILHO; CARDOSO, 2009).

Com a expansão das atividades industriais e de produção capitalista no Brasil, iniciase, na década de 1960, a estruturação de políticas para o ordenamento ambiental (ACSELRAD, 2001). O governo militar, pautado no protecionismo, visando regrar e ordenar o acesso aos bens naturais, cria o Código Florestal (Lei 4771, de 1965); estabelece o Ordenamento Pesqueiro e o da Mineração (através dos Decretos Lei 221 e 227, de 1967); decreta a Lei de Proteção a Fauna (Lei 5187, de 1967) e cria o Instituto Brasileiro de Desenvolvimento Florestal (Lei 289, de 1967). Em 1973, o governo, em resposta às pressões internacionais e às exigências do desenvolvimento econômico, criou a Secretaria Especial de Meio Ambiente - SEMA (SAISSE, 2012).

No Brasil, ainda em um contexto político ditatorial e de esfacelamento dos movimentos sociais, foi promulgada, em 1981, a Lei $6938^{6}$, que estabelece a Política Nacional de Meio Ambiente - PNMA. A política traz, em seus objetivos: Artigo 20: "[...] qualidade ambiental propícia à vida, visando assegurar, no País, condições ao desenvolvimento socioeconômico, aos interesses da segurança nacional e à proteção da dignidade da vida humana" (BRASIL, 1981; grifo nosso). A política ambiental brasileira estava, portanto em consonância com os fundamentos e aspirações mundiais: desenvolvimento econômico, com equidade social e preservação ambiental. Mas a questão que fica é: quem define essas aspirações em uma sociedade desigual? A Política Nacional de Meio Ambiente - PNMA, decretada em meio à ditadura militar, parece não ter sido construída para atender às aspirações do povo brasileiro.

Assim, nasceu o direito ambiental brasileiro, de forma centralizada, sem a participação popular, apesar de apresentar como incumbência do poder público, no artigo 225, "promover a educação ambiental a todos os níveis de ensino, inclusive a educação da comunidade, objetivando capacitá-la para a participação ativa na defesa do meio ambiente" (BRASIL, 1981), abrindo possibilidades de reivindicações de políticas públicas democráticas, com base na Lei.

Nesse mesmo sentido de possibilidades normativas, no cenário internacional, depois de Estocolmo, aconteceu, entre outros importantes encontros sobre educação ambiental, a Conferência Intergovernamental sobre Educação Ambiental (1977), em Tbilisi. A declaração de Tbilisi é considerada como um marco referencial para a educação ambiental. Esta coloca, ainda que de modo generalista, que "A educação ambiental deve ser dirigida à comunidade despertando o interesse do indivíduo em participar de um processo ativo de resolver problemas dentro de um contexto de realidades específicas" (TBILISI, 2014), trazendo, portanto, referências para uma abordagem interdisciplinar e participativa, que foram apropriadas por setores atuantes na formulação das normas federais brasileiras, a partir da década de 1990.

\section{O licenciamento ambiental offshore de petróleo}

Em 1974, acontece o grande salto da produção de petróleo, quando é descoberta a maior província petrolífera do Brasil, a Bacia de Campos, situada na região norte fluminense entre os estados do Rio de Janeiro e Espírito Santo (VAITSMAN, 2001; PIQUET, 2010). A

\footnotetext{
${ }^{6}$ Para efeitos do presente trabalho, importante citar os Decretos 88.351, de 1983, e 99.274, de 1990, que regulamentaram a PNMA (BRASIL, 1983, 1990).
} 
entrada e instalação de atividades de exploração e produção de petróleo, tanto na Bacia de Campos, como em qualquer localidade, gera impactos socioambientais sinérgicos, onde os grupos sociais da área de influência do empreendimento sofrem transformações significativas em seus espaços terrestre e marítimo (PIQUET, 2010; QUINTAS, 2005; SILVA, 2008). A entrada da indústria do petróleo no Brasil, apesar de altamente impactante, se deu sem a existência de políticas e instrumentos para que o processo de gestão ambiental ${ }^{7}$ subsidiasse a mediação de conflitos, o controle, a prevenção, a compensação ou a mitigação dos impactos socioambientais gerados por essa atividade.

Em 1981, o licenciamento ambiental é instituído no país pela PNMA. Este consiste em um conjunto de normas técnicas administrativas que estabelecem obrigações e responsabilidades para o poder público e para os empreendedores de atividades econômicas efetiva ou potencialmente poluidoras. Ou seja, estabelece as condições para o uso e exploração dos recursos naturais. Em seu artigo $10^{\circ}$, afirma que qualquer "construção, instalação, ampliação e funcionamento de estabelecimentos e atividades utilizadores de recursos ambientais, efetiva ou potencialmente poluidores [...] dependerão de prévio licenciamento ambiental".

No seu Artigo $9^{\circ}$ (incisos III e IV) traz a Avaliação de Impacto Ambiental - AIA, assim como o licenciamento ambiental e a revisão de atividades efetiva ou potencialmente poluidoras como dois dos treze instrumentos para se atingir os objetivos da PNMA (BRASIL, 1981). Portanto, esses dois instrumentos da PNMA (licenciamento e AIA) estão intrinsecamente relacionados e interligados à medida que a licença ambiental para empreendimentos de significativo impacto está condicionada à realização de estudos ambientais prévios. A mesma lei que traz o licenciamento ambiental como um dos instrumentos de sua política a nível federal, institui, em seu Artigo $6^{\circ}$, o Sistema Nacional de Meio Ambiente - SISNAMA, onde atribui aos “(...) órgãos e entidades da União, dos Estados, do Distrito Federal, dos Territórios e dos Municípios, bem como as fundações instituídas pelo Poder Público, responsáveis pela proteção e melhoria da qualidade ambiental [...]" a responsabilidade de darem cumprimento aos princípios da lei (BRASIL, 1981).

Dentre os órgãos criados, importante ressaltar o Conselho Nacional de Meio Ambiente - CONAMA, que teria, então, entre outras, a competência para estabelecer normas e critérios para o licenciamento de atividades efetiva ou potencialmente poluidoras (BRASIL, 1981). Em 1983, o Decreto Lei n. 88.351 regulamenta e estabelece as principais diretrizes do Sistema de Licenciamento Ambiental, vinculando a AIA ao licenciamento. O decreto reserva ao CONAMA a responsabilidade de "fixar os critérios básicos, segundo os quais serão exigidos estudos de impacto ambiental para fins de Licenciamento" (BRASIL, 1983).

Do conjunto de atribuições previstas na PNMA, o licenciamento ambiental pode ser considerado como um dos mais importantes e polêmicos instrumentos da política (SOUZA; NOVICKI, 2010). Pelo lado dos empreendedores e setores governamentais comprometidos com os interesses das corporações, o procedimento é burocrático e atrapalha o desenvolvimento; pelo lado dos críticos ao padrão de desenvolvimento, é permissivo e viabiliza qualquer tipo de empreendimento. $\mathrm{O}$ instrumento enfrenta, ainda, problemas de sobreposição de licenças em mesmo território, de fiscalização e acompanhamento, de cumprimento das condicionantes exigidas e político-econômicos (VULCANIS, 2014; SOUZA; NOVICKI, 2010).

\footnotetext{
${ }^{7}$ A gestão ambiental pública é aqui definida como um conjunto de procedimentos e medidas administrativas que têm o objetivo de gerenciar o uso de recursos naturais e os impactos ambientais causados nas áreas de influência de empreendimentos. Nesse sentido, é uma forma de o Estado de disciplinar os usos nos territórios e mediar conflitos existentes.
} 
Buscando dar uniformidade de tratamento aos diferentes processos de licença e resolver questões concretas, edita-se uma sequência de resoluções. Nesse contexto, dentre as resoluções CONAMA estabelecidas para o licenciamento, podemos destacar a n. 001/86, que trata da Avaliação de Impacto Ambiental - AIA; a n. 009/87, que trata de Audiência Pública, as resoluções n. 023/94 (BRASIL, 1994) e a n. 350/04 (BRASIL, 2004), específicas do Licenciamento offshore de petróleo, e a resolução n. 237/97, que busca dar resposta tanto a problemas de competência como de procedimentos gerais do licenciamento ambiental (BRASIL, 1986, 1987, 1994, 1997, 2004)

A resolução CONAMA n. 001/86 vem dar as diretrizes gerais para o uso e implementação da Avaliação de Impacto Ambiental - AIA na PNMA e, em seu Artigo $1^{\circ}$, considera como Impacto ambiental "[...] qualquer alteração das propriedades físicas, químicas e biológicas do meio ambiente, causada por qualquer forma de matéria ou energia resultante das atividades humanas [...)]" (BRASIL, 1986). Em seu artigo $2^{\circ}$, cita as atividades que dependerão da AIA, a serem submetidas à aprovação do órgão ambiental competente (e do IBAMA em caráter supletivo). Dentre as dezesseis atividades descritas, podemos destacar que as atividades da cadeia produtiva de petróleo se enquadram nos incisos: III: Portos e terminais de minério, petróleo e produtos químicos; V - Oleodutos, gasodutos, minerodutos, troncos coletores e emissários de esgotos sanitários e VIII - Extração de combustível fóssil (petróleo, xisto, carvão) (BRASIL, 1986).

Como parte do processo de AIA deve ser realizado um estudo interdisciplinar: o Estudo de Impacto Ambiental - EIA e seu respectivo Relatório de Impacto Ambiental RIMA, o EIA/RIMA. O EIA baseia-se nas Instruções Técnicas fornecidas pelo órgão ambiental envolvido no processo de Licenciamento e deve conter: I) o diagnóstico ambiental da área (levando em consideração as características bióticas, abióticas e socioeconômicas do local) ; II) análise dos impactos ambientais do projeto (através da identificação, previsão da magnitude, interpretação da importância, descrição e grau de reversibilidade dos impactos, etc.); III) a definição de medidas mitigadoras e IV) elaboração de programas de acompanhamento e monitoramento. O RIMA deve refletir, de forma objetiva e adequada, as informações e conclusões do EIA, em uma linguagem acessível ao público em geral e ficar disponível aos interessados. Segundo a resolução, o órgão ambiental responsável pelo licenciamento do empreendimento promoverá, sempre que julgar necessário, a realização de uma audiência pública para a divulgação dos resultados do EIA (BRASIL, 1981, 1987). Nessa ocasião, toda a população da área de influência e/ou das localidades vizinhas é convocada a participar da reunião, que é pública.

No sentido de garantir a participação dos interessados no processo de licenciamento ambiental, a resolução CONAMA n. 009/87 (em consonância com o também disposto na CONAMA n. 001/86) estabelece a audiência pública como instrumento do processo de licenciamento ambiental e dispõe sobre seus critérios. Traz, em seu Artigo $1^{\circ}$, enquanto sua finalidade: "expor aos interessados o conteúdo do produto em análise e do seu referido RIMA, dirimindo dúvidas e recolhendo dos presentes as críticas e sugestões a respeito". Define, também, que as audiências públicas são promovidas pelo órgão ambiental licenciador sempre que este julgar necessário fazê-lo, ou por solicitação de entidade civil, do Ministério Público, ou por cinquenta ou mais cidadãos. As atas das audiências públicas, assim como os documentos escritos e assinados que forem entregues ao presidente dos trabalhos da audiência, deverão servir de base, junto com o RIMA, para a análise e parecer final do licenciador quanto à aprovação ou não do projeto (BRASIL, 1987). É preciso destacar que as audiências não possuem caráter deliberativo e a competência da decisão continua centralizada no órgão licenciador. 
Visando o melhor controle e gestão ambiental das atividades da cadeia produtiva de petróleo, considerando-as bem distintas de outras atividades produtivas e do licenciamento usual, em 1994 a resolução CONAMA n. 023 estabelece critérios específicos para as atividades de exploração, perfuração e produção de petróleo e gás natural, denominando-a como EXPROPER. A resolução traz que o órgão ambiental competente, em conjunto com o empreendedor, ajustará um termo de referência com informações que darão subsídios para os estudos ambientais que serão solicitados em cada fase do licenciamento. A partir dessa normativa, as licenças são estabelecidas e seus respectivos estudos e projetos ${ }^{8}$.

Em 1997, considerando a necessidade de revisão dos procedimentos e critérios, e da regulamentação dos aspectos do sistema de licenciamento ambiental estabelecidos na PNMA que ainda não haviam sido definidos, a resolução CONAMA n. 237/97 altera artigos $\left(3^{\circ}\right.$ e $\left.7^{\circ}\right)$ da resolução n. 01/86 e dispõe sobre a revisão e complementação dos procedimentos e critérios utilizados para o licenciamento ambiental. Incluindo a ordem e prazos de validade das licenças ${ }^{9}$, os estudos ambientais necessários, a competência do órgão federal e dos estaduais e municipais. Em seu anexo, lista as atividades ou empreendimentos sujeitos ao licenciamento ambiental, considerando as atividades de exploração e produção de petróleo e gás como poluidoras (BRASIL, 1997).

Segundo a Política Nacional de Meio Ambiente, a competência do licenciamento estava restrita aos estados e ao Instituto Brasileiro de Meio Ambiente e dos Recursos Naturais Renováveis (IBAMA) em caráter supletivo, no entanto, a partir da Constituição Federal (Artigo $2^{\circ}$ ) (BRASIL, 1988) e com base na resolução CONAMA n. 237/97 (Artigo 20), foi facultado ao município o licenciamento ambiental local, condicionado, entre outros aspectos, à implementação de seus respectivos Conselhos Municipais de Meio Ambiente - CMMA (SOUZA; NOVICKI, 2010).

\section{A educação ambiental crítica do licenciamento offshore}

Constituem medidas mitigadoras no licenciamento ambiental na indústria offshore a implementação de projetos e programas ambientais, que devem constar nos estudos apresentados para a obtenção da LO. Sendo assim, a manutenção da LO está condicionada à execução desses programas, segundo as exigências do órgão ambiental licenciador. Dentre as

\footnotetext{
${ }^{8}$ I) Licença Prévia de Perfuração - LPper, autorizando a atividade de perfuração, quando apresentado o Relatório de Controle Ambiental (RCA). O RCA elaborado pelo empreendedor deve conter a descrição da atividade de perfuração, riscos ambientais, identificação dos impactos e medidas mitigadoras. II) Licença de Perfuração para Pesquisa - LPpro, autorizando a produção para a pesquisa de viabilidade econômica da jazida, quando apresentado o Estudo de Viabilidade Ambiental (EVA). O EVA deve conter o plano de desenvolvimento da produção para a pesquisa pretendida, com avaliação ambiental e indicação das medidas de controle a serem adotadas. III) Licença de Instalação - LI, autoriza a instalação das unidades e sistemas necessários à produção e ao escoamento, após aprovado o EIA (para campos onde ainda não houve atividade de produção) ou o Relatório de Avaliação Ambiental (RAA). O RAA é apresentado em campos onde já houve produção, ou seja, contém o diagnóstico ambiental da área onde já se encontra implantada a atividade, complementando-se com descrição dos novos empreendimentos ou ampliações, identificação e avaliação do impacto ambiental e medidas mitigadoras adotadas, considerando a introdução de outros empreendimentos. IV) Licença de Operação - LO, autoriza o início da operação do empreendimento, após a aprovação do Plano de Controle Ambiental (PCA). O PCA contém os projetos executivos de minimização, mitigação e compensação dos impactos ambientais avaliados nas fases da LPper, LPpro e LI (BRASIL, 1994).

${ }^{9}$ Determina a ordem e os prazos de validade das licenças, em que a Licença Prévia (LP) deve ser inferior a cinco anos; a Licença de Instalação (LI) inferior a seis anos e a última, a Licença de Operação (LO), deve ter no mínimo quatro anos e no máximo dez anos.
} 
condicionantes de licença da indústria offshore estão: Projeto de Controle da Poluição; Programa de Monitoramento Ambiental; Plano de Emergência Individual; Projeto de Comunicação Social; Projeto para a Compensação da atividade de pesca artesanal; Programa de Educação Ambiental de Trabalhadores e o Programa de Educação Ambiental (com os grupos sociais impactados pela atividade licenciada).

No que se refere aos programas de educação ambiental, as normas estabelecem diretrizes e princípios inseridos na perspectiva crítica, possibilitando uma atuação direta nos conflitos ambientais e no promover a reversão das injustiças ambientais. Para isso, são exigidos processos educativos que impulsionem a articulação e a participação de grupos sociais em condições de vulnerabilidade em processos decisórios da política ambiental e demais políticas públicas que afetam a reprodução do modo de vida de tais grupos, podendo culminar na transformação das realidades de vida dos sujeitos da ação (LOUREIRO, 2009). Em suma, o processo educativo é a resultante dos processos de mobilização, organização e participação social, favorecendo o fortalecimento dos grupos sociais impactados por esses empreendimentos e envolvidos em conflitos de uso dos recursos naturais (QUINTAS 2005; IBAMA, 2005; ALIER, 2011).

Quando a dimensão conflitiva é tratada, torna-se possível compreender que os problemas e os temas ambientais não são neutros ou possíveis de serem resolvidos apenas pela intervenção técnica. A historicidade passa a ser constitutiva da atividade pedagógica, não cabendo mais como suficiente a constatação do problema ou o voluntarismo para resolvê-lo, sendo vital a problematização que leve ao conhecimento da sua dinâmica causal e dos agentes sociais envolvidos. Isso politiza a educação ambiental e exige de seus sujeitos posicionamento quanto a projetos de sociedade e de sustentabilidade. A necessidade de se posicionar leva a uma prática reflexiva da realidade, à compreensão complexa das responsabilidades e direitos de indivíduos-grupos-classes, a uma prática que atue tanto no cotidiano quanto na organização política para as lutas sociais.

Dentro do Ibama, os projetos de educação ambiental a serem implementados como condicionantes de licenças de produção offshore de petróleo são avaliados, fiscalizados e acompanhados pela Coordenação Geral de Petróleo e Gás - CGPEG. Suas orientações decorrem de um acúmulo de discussões e experiências sobre as finalidades da educação na gestão ambiental pública, capitaneadas pela extinta Coordenação Geral de Educação Ambiental - CGEAM/Ibama, em um movimento teórico-prático que remonta ao início da década de 1990 (LOUREIRO; SAISSE; CUNHA, 2013; LOUREIRO; SAÍSSE, 2014).

Assim, em consonância com esse histórico institucional e respaldado pelas diretrizes gerais da Política Nacional de Educação Ambiental (Lei n. 9795/99), em 2005, foi publicado pelo Ibama um documento norteador intitulado "Orientações pedagógicas do IBAMA para elaboração e implementação de programas no licenciamento de atividades de produção e escoamento de petróleo e gás natural”. Neste é destacada a importância da percepção dos atores sociais acerca dos impactos ambientais sofridos pelas comunidades do entorno do empreendimento e sobre a importância de um processo educativo que:

[...] possibilite ao indivíduo perceber-se como sujeito social capaz de compreender a complexidade da relação sociedade-natureza, bem como comprometer-se em agir em prol da preservação de riscos e danos socioambientais causados por intervenções no meio físico natural e construído [...]. Importante instrumento para a implementação de quaisquer empreendimentos que, de alguma forma, afetem o meio ambiente e, por consequência, a qualidade de vida das populações (IBAMA, 2005, p.3). 
Em 2010, foi publicada a Nota Técnica CGPEG/DILIC/IBAMA - NT 01/10 (IBAMA, 2010) que traz diretrizes para a elaboração, execução e desenvolvimento dos programas de educação ambiental desenvolvidos regionalmente, nos processos de licenciamento ambiental dos empreendimentos marítimos de exploração e produção de petróleo e gás. Vale destacar que nessa NT são propostas linhas de ação que constituem frentes de atuação, estruturadas em projetos, para compor um programa (IBAMA, 2010). Das linhas de ação propostas na Nota Técnica, destaca-se a Linha A, a saber:

Organização comunitária para a participação na Gestão Ambiental, no âmbito do licenciamento ambiental: desenvolver processos formativos junto ao público prioritário (...) desenvolver processos formativos para subsidiar a intervenção qualificada de determinados grupos sociais em processos decisórios de distribuição de custos/benefícios a partir da exploração de recursos naturais. (...) o estímulo à organização dos segmentos sociais (IBAMA, 2010, p.4).

As outras linhas de ação propostas são: Linha de Ação B - Controle social da aplicação de royalties e de participações especiais da produção de petróleo e gás natural; Linha de Ação $\mathrm{C}$ - Apoio à democratização, à discussão pública e à fiscalização do cumprimento das diretrizes de Planos Diretores municipais; Linha de Ação D - a ser proposta pela empresa; Linha de Ação E - Projetos compensatórios para populações impactadas por empreendimentos de curto prazo; Linha de Ação F - Apoio à discussão e ao estabelecimento de acordos para a gestão compartilhada das atividades na zona marítima (IBAMA, 2010).

No ano de 2012, inspirada e em consonância com a NT n. 01/10 - CGPEG/Ibama, específica para o licenciamento offshore da indústria de petróleo, foi publicada pelo Ibama a Instrução Normativa n. 02/12, que traz as bases técnicas para a elaboração dos programas de educação ambiental de todas as atividades licenciadas a nível federal. A instrução preconiza que os programas de educação ambiental (PEAs) devem ser direcionados aos grupos sociais da área de influência da atividade em processo de licenciamento. Em seu artigo $3^{\circ}$ enfatiza que o "PEA deve compreender a organização de processos de ensino-aprendizagem, objetivando a participação dos grupos sociais das áreas de influência"; traz, também, que a elaboração do PEA deve ser feita a partir de um diagnóstico socioambiental com metodologias participativas, e que os projetos considerem as especificidades locais, os impactos gerados pelas atividades e "objetivem a promoção do protagonismo dos diferentes grupos sociais na área de influência da atividade" (IBAMA, 2012, p.130).

Assim, destacam-se, nesses três últimos documentos apresentados (orientações pedagógicas, NT 01/10 e IN 02/12) a importância do enfrentamento às desigualdades sociais, reproduzidas nas injustiças ambientais, e da construção do caráter público das políticas ambientais, particularmente dos instrumentos da gestão ambiental. Para isso, são afirmadas diretrizes que reforçam a criticidade, a dialogicidade e a historicidade das atividades educativas e a adoção de metodologias participativas, voltadas especialmente para a organização e mobilização popular na construção de espaços públicos e na conquista de direitos. Ainda em relação a esses instrumentos normativos, podemos destacar três aspectos indispensáveis a todo e qualquer projeto de educação ambiental no licenciamento: importância estratégica de se trabalhar com sujeitos pertencentes a grupos vulneráveis afetados pelos impactos da cadeia produtiva licenciada; abordagem pedagógica centrada nos impactos da cadeia produtiva licenciada e nos problemas e conflitos daí decorrentes, identificando quem é quem, quem gera o que e com quais interesses; execução de projetos e ações voltados para a organização, mobilização, qualificação, intervenção social e fortalecimento de processos políticos, econômicos e culturais dos sujeitos prioritários do processo educativo (os grupos vulneráveis) como condição para sua autonomia e 
enfrentamento das desigualdades no acesso e uso da natureza e na garantia do ambiente como bem comum.

\section{Considerações Finais}

Em nome do interesse público, o Estado, por meio da gestão ambiental, é o responsável por gerenciar, regular usos e mediar conflitos (potenciais ou explícitos) entre os agentes sociais no acesso e apropriação dos recursos naturais. Entretanto, o exercício da gestão ambiental pública não é neutro na efetivação de seus instrumentos de controle e decisão sobre o que pode ou não ser feito e sobre qual atividade pode ou não ser licenciada, expressando as correlações de força existentes na sociedade.

Nesse movimento contraditório, dentro de um Estado dirigido por frações das classes dominantes, algumas normas federais, particularmente voltadas para a materialização da educação ambiental no licenciamento ambiental federal, trazem respaldo jurídico-normativo para a execução de programas e projetos de interesse público. Naquilo que compete ao Ibama (nem sempre em consonância com o que acontece em estados e municípios, que estabelecem diretrizes próprias e diferenciadas), realizar uma educação ambiental com orientações teóricas e metodológicas críticas, voltadas à justiça ambiental, é algo que implica em tensões internas e externas ao órgão, pois vai na contramão dos interesses econômicos dominantes e de uma lógica de uso dos instrumentos públicos da gestão ambiental voltada para legitimar os grandes empreendimentos e sua forma desigual de organização territorial.

Portanto, é importante que se olhe para a educação ambiental nos instrumentos da gestão ambiental pública como uma conquista de caráter público, como um acúmulo de mais de 20 anos de construção no interior da estrutura de Estado, e, igualmente, como algo que é disputado e realizado em um processo econômico destrutivo e expropriador. Assim posto, se a educação ambiental não for apropriada por trabalhadores, povos tradicionais, grupos de periferia, povos originários entre outros, se converterá em meio de reprodução ideológica da sociedade atual, deixando de ser um instrumento público, sob o protagonismo dos que historicamente ficaram excluídos dos processos decisórios, de conquista de direitos e de usos justos dos benefícios materiais decorrentes das atividades econômicas licenciadas.

\section{Referências}

ACSELRAD, H. Sustentabilidade e Desenvolvimento: modelos, processos e relações. Cadernos de Debate Brasil Sustentável e Democrático - FASE, Rio de Janeiro, no 5,1999. p. 1 - 48.

ACSELRAD, H. Políticas ambientais e construção democrática. In: VIANA, G.; SILVA, M; DINIZ, N. (Orgs.). O Desafio da Sustentabilidade: um debate socioambiental no Brasil. São Paulo: Fundação Perseu Ábramo, 2001. P. 75-96.

ALIER, J. M. Ecologismo dos pobres. Conflitos ambientais e linguagens de valoração. São Paulo: Contexto, 2011.

BRASIL. Constituição da República Federativa do Brasil de 1988. Brasília, Presidência da República, Casa Civil, 1988.

BRASIL. Lei Federal $n^{\circ}$. 6.938, de 31 de agosto de 1981. [Online]. Dispõe sobre a Política Nacional do Meio Ambiente, seus fins e mecanismos de formulação e aplicação, e dá outras providências. Brasília: Casa Civil, 1981. Disponível em: <http://www.planalto.gov.br/ccivil_03/LEIS/L6938.htm>. Acesso em: 23 ago. 2014. 
BRASIL. Decreto Lei $n$. 99.274. Regulamenta a Lei ${ }^{\circ}$ 6.902, de 27 de abril de 1981, e a Lei $\mathrm{n}^{\circ}$ 6.938, de 31 de agosto de 1981, que dispõem, respectivamente sobre a criação de Estações Ecológicas e Áreas de Proteção Ambiental e sobre a Política Nacional do Meio Ambiente, e dá outras providências. Brasília, Presidência da República, Casa Civil, 6 de junho de 1990.

BRASIL. Decreto Lei $n^{\circ} 88.351$, de $1^{\circ}$ de Junho de 1983. [Online]. Regulamenta a lei $\mathrm{N}^{\circ} 6.938$, de 31 de agosto de 1981, e a Lei $n^{\circ}$ 6.902, de 27 de abril de 1981, que dispõem, respectivamente, sobre a Política Nacional do Meio Ambiente e sobre a criação de Estações Ecológicas e Áreas de Proteção Ambiental, e dá outras providências. Brasília: Presidência da República, Casa Civil, 1983. Disponível em: $\quad<$ http://www2.camara.leg.br/legin/fed/decret/1980-1987/decreto-88351-1-junho-1983-438446norma-pe.html>. Acesso em: 23 ago. 2014.

BRASIL. Ministério do Meio Ambiente. Conselho Nacional do Meio Ambiente. Resolução CONAMA $n^{\circ}$ 001, de 23 de janeiro de 1986 [Online]. Estabelece as definições, as responsabilidades, os critérios básicos e as diretrizes gerais para uso e implementação da Avaliação de Impacto Ambiental como um dos instrumentos da Política Nacional do Meio Ambiente. Brasília: MMA/CONAMA, 1986. Disponível em: <http://www.mma.gov.br/port/conama/processos/61AA3835/LivroConama.pdf>. Acesso em: 23 ago. 2014.

BRASIL. Ministério do Meio Ambiente. Conselho Nacional do Meio Ambiente. Resolução CONAMA n. ${ }^{\circ}$ 009, de 03 de dezembro de 1987. Dispõe sobre a realização de Audiências Públicas no processo de licenciamento ambiental. Diário Oficial da República Federativa do Brasil, Brasília, DF, 05 jul. 1990, Seção I, p. 12.945.

BRASIL. Ministério do Meio Ambiente. Conselho Nacional do Meio Ambiente. Resolução CONAMA $n^{o}$ 237, de 19 de Dezembro de 1997 [Online]. Revisa os procedimentos e critérios utilizados no licenciamento ambiental, de forma a efetivar a utilização do sistema de licenciamento como instrumento de gestão ambiental, instituído pela Política Nacional do Meio Ambiente. Brasília: MMA, 1997. Disponível em: <http://www.mma.gov.br/port/conama/res/res97/res23797.html>. Acesso em: 23 ago. 2014.

BRASIL Resolução CONAMA 023/94. Institui procedimentos específicos para o licenciamento de atividades relacionadas à exploração e lavra de jazidas de combustíveis líquidos e gás natural. Diário Oficial da República Federativa do Brasil, Brasília, DF, 30 dez. 1994. p. 21345-21346.

BRASIL Resolução CONAMA 350/04. Dispõe sobre o licenciamento ambiental específico das atividades de aquisição de dados sísmicos marítimos e em zonas de transição. Diário Oficial da República Federativa do Brasil, Brasília, DF, 20 ago. 2004, págs. 80-81.

CASTRO, M. L.; CANHEDO JR, S. G. Educação ambiental como instrumento de participação. In PHILIPPI-JR, A.; PELICIONI, M. C. F. (Orgs.). Educação ambiental e sustentabilidade. Barueri: Manole, 2005. p. 401-411.

GUSMÃO, A. C. F; DI MARTINI, L. C. Gestão Ambiental na Indústria. Rio de Janeiro: SMS Digital, 2009.

HARVEY, D. O enigma do capital e as crises do capitalismo. São Paulo: Boitempo, 2011.

INSTITUTO BRASILEIRO DO MEIO AMBIENTE E DOS RECURSOS NATURAIS RENOVÁVEIS - IBAMA. Orientações Pedagógicas do IBAMA para Elaboração e Implementação de Programas de Educação Ambiental no Licenciamento de Atividades de Produção e Escoamento de Petróleo e Gás Natural. Brasília: IBAMA, 2005. 
INSTITUTO BRASILEIRO DO MEIO AMBIENTE E DOS RECURSOS NATURAIS RENOVÁVEIS - IBAMA. Nota Técnica Cgpeg/Dilic/Ibama $N^{o}$ 01/10. 10 de fevereiro de 2010. Diretrizes para a elaboração, execução e divulgação dos programas de educação ambiental desenvolvidos regionalmente, nos processos de licenciamento ambiental dos empreendimentos marítimos de exploração e produção de petróleo e gás. Brasília: IBAMA, 2010.

INSTITUTO BRASILEIRO DO MEIO AMBIENTE E DOS RECURSOS NATURAIS RENOVÁVEIS - IBAMA. Instrução Normativa Cgpeg/Dilic/Ibama No 02/12. Diário Oficial da República Federativa do Brasil, Brasília, DF, 29 de Março de 2012, Seção I, p. 130.

LA PRESTRE, P. Ecopolítica Internacional. São Paulo: Senac, 2000.

LOUREIRO, C. F. B. O movimento Ambientalista e o pensamento crítico. Uma abordagem política. Rio de Janeiro: Quartet, 2003.

LOUREIRO, C. F. B. Educação ambiental no licenciamento: aspectos legais e teórico-metodológicos. In ___ (Org.). Educação ambiental no contexto de medidas mitigadoras e compensatórias: o caso do licenciamento. Salvador: IMA, 2009. P. 17-42.

LOUREIRO, C. F. B.; SAISSE, M. E CUNHA, C. C. Histórico da educação ambiental no âmbito federal da gestão ambiental pública: um panorama da divisão do IBAMA à sua reconstrução no ICMBio. Desenvolvimento e Meio Ambiente, Curitiba, v. 28, p. 57-73, Jul./Dez. 2013.

LOUREIRO, C. F. B.; SAISSE, M. Educação ambiental na gestão ambiental pública brasileira: uma análise da SEMA ao ICMBio. Revista educação pública, Cuiabá, v. 23, n. 52, p. 105-129, Jan./Abr. 2014.

MACHADO, A. A. O Local e o Global na Estrutura da Política Ambiental internacional: a construção social do acidente químico ampliado de Bhopale da convenção174 da OIT. Contexto Internacional, Rio de Janeiro, v. 28, n. 1, p. 7-51, Jan./Jun. 2006.

MIRANDA, C. M.; CASTILHO, N. A. N.; CARDOSO, V. C. C. Movimentos Sociais e participação popular: Luta pela conquista dos direitos sociais. Revista Católica, Uberlândia, v.1, n.1, p. 176-185, 2009.

MONTAÑO, C.; DURIGUETTO, M. L. Estado, Classe e Movimento Social. São Paulo: Cortez, 2010.

PIQUET, R. Petróleo, Royalties e Região. Rio de Janeiro: Garamond, 2010.

QUINTAS, J. S. Introdução à Gestão Ambiental Pública. Brasília: Edições IBAMA, 2005.

SAISSE, M. Histórico da educação ambiental pública: um panorama desde a SEMA ao ICMBio. In: LOUREIRO, C. F. B. L. (Org.) Gestão pública do ambiente e educação ambiental: caminhos e interfaces. São Carlos, RIMA, 2012. P. 57-74.

SILVA, J. M. C. Petróleo e Gás na Bacia de Campos (RJ): percepção dos impactos ambientais pela população. 2008. 187 folhas. Dissertação (Mestrado em Ecologia) - Programa de Pós-Graduação em Ecologia, Instituto de Biologia, Universidade Federal do Rio de Janeiro, Rio de Janeiro, 2008. Disponível em <http://livros01.livrosgratis.com.br/cp094444.pdf>. Acesso em: 23 ago. 2014.

SOUZA, D. B.; NOVICKI, V. Conselhos Municipais de Meio Ambiente. Estado da Arte, Gestão e Educação Ambiental. Brasília: Liber Livro, 2010. 
TBILISI. Declaração de Tbilisi, $1977 . \quad$ Disponível em: http://www.mma.gov.br/port/sdi/ea/deds/pdfs/decltbilisi.pdf > Acesso em: 16 mai. 2014.

VAITSMAN, M. O petróleo no império e na república. Rio de Janeiro: Interferência, 2001.

VULCANIS, A. Os problemas do licenciamento ambiental e a reforma do instrumento. Portal Planeta Verde [Online] 2014. Disponível em: http://www.planetaverde.org/arquivos/biblioteca/arquivo 20131031141015 4012.pdf. Acesso em: 13 mar. 2014.

Versão recebida em: 20/08/2014

Aceite em: 18/03/2016 